\title{
The Acute Care Services Production Process's Efficiency: A DEA Network Model for the Italian Hospitals
}

\author{
By Claudio Pinto*
}

\begin{abstract}
The paper conceptualize the production process of the hospital's acute care services as a network of two sub-processes. A Constant Returns to Scale and Variable Returns to Scale Data Envelopment Analysis network model allows us to estimates relational and sub-process efficiency. Our results show that under the Constant Returns to Scale assumption the Data Envelopment Analysis network model results in a $0.459 \%$ level of efficiency on average, while the Data Envelopment Analysis model in a 0.590\% efficiency level. Additionally, the Variable Returns to Scale efficiency scores are estimated to be around $0.849 \%$ and $0.655 \%$ respectively. The efficiency of the medical and assistance sub-processes are individually measured and found to be at the $0.485 \%$ and of $0.647 \%$ levels respectively under Constant Returns to Scale assumption, and at the $0.564 \%$ and $0.706 \%$ levels under Variable Returns to Scale. The relational efficiency of the second sub-process is estimated to be around $0.93 \%$ and 1.22 respectively under Constant Returns to Scale and Variable Returns to Scale. Concluding statistical tests confirm that modeling the relationship between the two sub-processes using a relational model influences the efficiency measurement, affecting consequently the policy implications.
\end{abstract}

Keywords: Data Envelopment Analysis, Efficiency, Hospital services, Network Data Envelopment Analysis.

\section{Introduction}

The health system in Italy, like other European health systems, is facing the stress of high public debt limiting the availability of public resources for them. In order to get access to public fund, the health care system is required to improve efficiency, reduce costs and maintain the quality of care. Thus, managers and policy makers' main target is to improve the performance of health organizations as well as the performance of the general public system. The introduction of the Diagnosis Related Group (DRG) system in Italy (Taroni 1996) reflects this generalized effort to reduce hospital costs (Barbetta and Zago 2007, Fattore and Torbica 2006), representing the greater proportion of current public health expenditures. In the managerial sciences, Data Envelopment Analysis (DEA) (Cooper et al. 2007) and the Free Disposable Hull (FDH) (Deprins et al. 1984) are the frontier non parametric methods used to estimate efficiency and measure performance of the hospital sector as well as of other health organizations (Hollingsworth 2008). The parametric version of medical efficiency estimation is the Stochastic Frontier Analysis (SFA). Despite its prevalence in the relevant literature, DEA show some limits in

\footnotetext{
${ }^{*}$ Postdoctoral Fellowship, University of Salerno, Italy.
} 
contrast to its advantages (Daraio and Simar 2008), not allowing to thorougly examine the activities within the Decision Making Units (DMU). A way to do this is to consider the DMU as internally consisting of different parts and as a network of sub-processes on the external (Fare and Grosskopf 2000, Kao 2009a). In the present study, we propose a conceptualization of the production process of acute services in the hospitals as a network consisting of two subprocesses. A DEA network model is employed to estimate the relational efficiency of the entire process and the efficiency of the two sub-processes. The paper is organized as follows: the next section presents the literature review while in the following one, the conceptualization of the production process of the hospital's acute care as a network is described. Subsequently, the inputs and outputs used in DEA and DEA network are presented along with the descriptive statistics of the data on which the analysis is based. Finally, the results, the discussion and the conclusions are included in the last sections.

\section{Literature Review}

The Data Envelopment Analysis (DEA) (Cooper et al. 2007) has been extensively implemented for the efficiency measurement in the hospital sector (Hollingsworth 2008, Liu et al. 2013) around the world. In Italy, Cellini et al. (2000) apply DEA to measure the efficiency of hospital production and investigate its determinants. The authors find that on average, in their sample of 1,183 Italian hospitals in 1996, the pure technical inefficiency is $35 \%$, the scale inefficiency is $11 \%$ while the degree of technical inefficiency is $42.5 \%$. Following the regression analysis of the efficiency determinants, the authors conclude that, among other things, the ownership per se is not relevant; the effect of the individual market share upon efficiency is positive when regressed on pure technical efficiency but is not when regressed on overall efficiency; the structure of the regional market seems to play a relevant role while the density of hospitals has a negative effect. Barbetta and Zago (2007), attempting to identify behavioural differences between public and private not-for-profit hospitals after the introduction of DRG, estimates technical efficiency using DEA and other parametric approaches on a sample of 531 hospitals observed during the the period 1995-20001. It is found that the Not For Profit (NFP) private hospitals appear to be more efficient than their public counterparts. A decline trend in the efficiency of both types of health care centers is also observed, with the trend being more intense in the case of the private NFP. Yet, the efficiency scores between the two type of hospitals are statistically different for the initial period $(1995,1996,1997)$. In the final years (1999 and 2000), NFP and public hospitals do not have significantly different efficiency scores. Thus, the authors conclude that there is a convergence in the efficiency scores between NFP and public hospitals as soon as the common DRG-based payment system is implemented. Siciliani (2006) using a longitudinal sample and

${ }^{1}$ 1995-1997: before introduction DRG system, 1998-2000: later introduction of DRG system in Italy. 
implementing parametric as well as non parametric techniques compares the technical efficiency of a sample of 17 Italian hospitals. In Greece, Kontodimopoulos et al. (2006), using DEA, investigate the efficiency of a set of small-scaled hospitals known as hospital-health centres (HHCs) located in remote areas and serving small, local populations. The authors find that the technical inefficiency is $27.77 \%$ in the case of units with preventive medicine and $25.23 \%$ in the units without it. Aletras et al. (2007) estimate the impact of the 2001 reform on the technical and scale efficiency on general acute hospitals in the National Health System (NHS) in Greece. The authors find that both the technical and scale types of efficiency have been reduced after the implementation of reforms. Lyroudi et al. (2006) investigate the productivity performance of 10 clinics in a public hospital located in Thessaloniki using DEA and DEA-Malmquist productivity indeces. They find that the efficiency of the hospital clinics improved, varying a lot from month to month. Giokas (2001), using parametric and non-parametric methods estimates the efficient marginal costs of hospital services (inpatient days in medical care, inpatient days in surgical area, etc.) of public, general and teaching hospitals. The author concludes that there are potential savings of up $20 \%$ on hospitals spending; the difference between the actual and efficiency costs is $27 \%$ for general hospitals and $16 \%$ for teaching hospitals; non-efficient hospitals could produce the same result, if the daily cost per patient was reduced by $26 \%$. Yet, al least $4 \%$ of the health care costs in the gross domestic product are due to inefficiency created by public, general and teaching hospital. Athanassopoulos et al. (1999) using DEA investigate the degree of utilisation of resources and the productivity efficiency of the general hospitals using two alternative models focused on production and cost efficiency. The authors' results indicate substantial efficiency improvement. All the studies cited so far use the standard DEA model, analysing the use of resources to produce services ignoring the internal hospital activities. From 2000 onwards, some authors as Fare and Grosskopf (2000) proposed a way to take a look inside the "black box" proposing different DEA network models. More recently, Kao proposed an updated DEA network model decomposing efficiency measurement in sub-processes and also discussed several applications of these models (Kao 2009a, Kao 2009b, Kao 2014, Kao and Hwang 2008). A quite representative application of the DEA network for hospitals can be found in the paper by Kawaguchi et al. (2014). The authors investigate two heterogeneous internal hospital organizations in Japan: the medical examinations' division and the administrative division. The first provides medical services while the second is in charge of the business management. In order to perform the evaluation, the authors apply a dynamicnetwork (DN) data envelopment analysis and they find that, on average, the overall efficiency in the DN model was 0.854 in 2007 while the dynamic efficiency from 2007 and 2009 was slightly lower. Yet, the average efficiency of administrative division decreased from 0.867 in 2007 to 0.851 in 2009 while the average efficiency of the medical-examination division increased from 0.858 in 2007 to 0.870 in 2009. 


\section{The Acute Care Services as a Network of Two Sub-processes}

The hospital services in Italy

In Italy, hospital services are delivered by public and accredited private organization. They are organized in departments and in simple and complex operational units as well as technical support for the operational units, (as, for example, clinical exams at the medical activities), is also offered. The responsibility of the hospital's organization is of regional nature (Bordignon et al. 2002, Cellini et al. 2000, France et al. 2005). The services offered by hospital are the following:

- Emergency;

- Ordinary hospitalization;

- Day hospital;

- Day surgery;

- Hospitalization at home;

- Rehabilitative services;

- Long-term services;

- Pick-up, delivery and treatment of hemocomponents and transfusion services;

- Transplant services;

- Storage and delivery of tissues.

\section{The Hospital's Acute Care Service as A Network of Two Sub-Process}

In this section, the conceptualization of the production process of the hospital acute care service as a network of two sub-processes is developed. A graphical representation can be found in Figure 1.

Figure 1. Graphical Representation of the Hospital's Acute Care Service Production as a Network of Two Sub-Processes

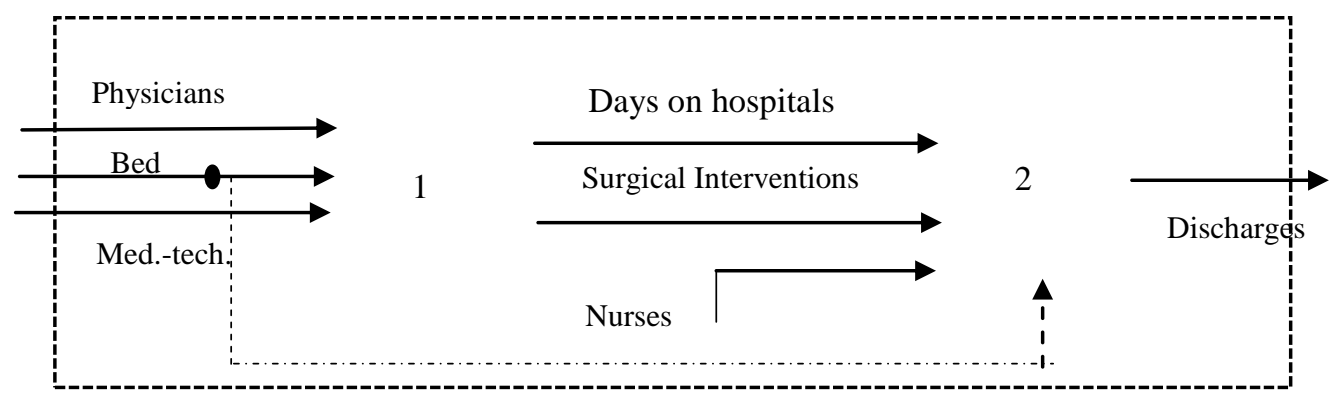

Source: Author's estimations.

According to Figure 1, the inpatients admitted to the hospitals occupy beds in ordinary or daily modes and receive medical care by physicians (medical 
care or surgical operations) and/or instrumental services (for example the ray-X or other) by medical-technical staff. The outputs of the medical sub-processes are the surgical interventions, provided by the physicians, the days spent in the hospital, fixed by the hospital procedures, the assistance services, directly connected to the need of inpatients after medical interventions and offered by nurses. These outputs are inputs for the second sub-process as well. Obviously, before being discharged and during the days spent in the hospital, patients receive assistance services by nurses. After the completion of the second subprocess, the patient is discharged from the hospital. The efficiency of this whole process and sub-processes can be estimated using a DEA network model. The sub-processes are interconnected in proportion of their usage (here stated at $30 \%$ for medical care and $70 \%$ for the assistance services from the basis of the ratio between physicians and nurses), assuming that the proportion between physicians and nurses reflect the ratio of interconnection between the two types of activities. We categorize the services received by the patients from their discharge papers to two categories: ordinary, day-hospital and surgical services.

\section{The DEA and the DEA Network}

In this section, we show the inputs, outputs and the relational variables used to solve the DEA network model (Table 1) in accordance with Figure 1.

Table 1. DEA Network Inputs, Outputs and Relational Variables, 2011

\begin{tabular}{|l|l|l|}
\hline \multicolumn{3}{|c|}{ Relational model } \\
\hline Inputs & Outputs & Relational variables \\
\hline Physicians & Ordinary discharges & Surgical intervention \\
\hline Ordinary beds & Day-hospital discharges & Days-on hospitals \\
\hline Day-hospital beds & Surgical discharges & Shared resources* \\
\hline Day-surgery beds & & \\
\hline Nurses (second sub-process) & & \\
\hline Medical-technical staff & & \\
\hline
\end{tabular}

Source: Author's estimations.

Note: $(*)$ indicate the variables (beds) that the sub-process share in the defined proportion. The other are intermediate inputs.

In this model, nurses are considered as inputs of the second sub-process but not as relational variables. The adoption of this approach to the nurses variable seems to fit better to the real hospital conditions. 
The baseline DEA network model employed in the context of the present study is the following:

$$
\begin{aligned}
& \max \sum_{r=1}^{s} u_{r} Y_{r k} * i \mathrm{~cm} \\
& \text { s. } t_{x} \sum_{i=1}^{m} v_{i} X_{i k}=1 \text {. } \\
& \sum_{r=1}^{g} u_{r} Y_{r k}-\sum_{i=1}^{m} v_{i} X_{i k} \leq 0, \\
& \sum_{h=1}^{4} w_{h 1 k} z_{k 1 k}-\sum_{i=1}^{F} w_{i k} X_{i 1 k} \leq 0 \text { 。 } \\
& \sum_{r=1}^{J} u_{r} Y_{r k 2} * i c m-\sum_{k=1}^{q} w_{h 2 k} Z_{\mathfrak{h} 2 k} \leq 0, \\
& \text { with }\left(u_{s} v_{s} w\right) \geq 0
\end{aligned}
$$

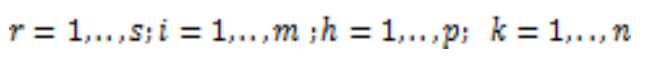

We have $\mathrm{k}=574$ public hospitals that use $\mathrm{m}$ inputs $\left(x \in R^{m}\right)$ and produce $\mathrm{s}$ outputs $\left(y \in R^{s}\right)$ while two sub-process are considered for each hospital. In the first sub-process, $\mathrm{p}$ inputs are used, $X_{i 1 k} \in R^{p}$, and $\mathrm{q}$ outputs are produced, $Z_{h 1 k} \in R^{q}$. The second sub-process uses $\mathrm{t}=\mathrm{q}$ inputs $Z_{h 2 k} \in R^{t=q}$ and produce $\mathrm{f}=\mathrm{s}$ outputs $\left(Y_{r k 2} y \in R^{f}\right)$. The weights $(\mathrm{w})$ of the outputs of the first sub-process are equal to $(\mathrm{w})$ the inputs of the second sub-process. To better understand the concept of the shared resources consider the variable "beds", being an input to the first sub-process $(\mathrm{x})$, in the following manner: beds $=$ beds $* 0.30$, while the same variable could be defined as beds $=$ beds $* 0.70$ in the context of the inputs vector of the second sub-process $(\mathrm{z})$. A way to fix this inconsistency in the beds usage proportion is to use the ratio medical staff/beds or the ratio medical staff/nurses. The objective function of the program weighted discharges with case mix index (Aletras et al. 2007, Grosskopf and Valdmanis 1993) is used.

The inputs and outputs of the model are selected following the relevant literature on this particular subject (among other Cellini et al. 2000, Ozcan et al. 1992, O'Neill et al. 2008). The outputs of the system are categorized in the following groups: surgical, ordinary and day-hospital discharges. As Gerdtham et al. (1998) indicate, in agreement to Pinto's (2014) findings providing evidence of their effect on the performance of Italian hospitals, the outputs of the relational model, as well as of the second sub-process, are weighted using the Case Mix Index (ICM). According to our relational model other variables, such as the surgical discharges and days on hospitals, are considered to be intermediate variables. In the same sense, the beds are considered as shared resources between the sub-processes. The inputs of the system, also being the inputs of the firs sub-process, are beds, categorized in ordinary, day surgery 
and day-hospital services as well as serviced offered by physicians and medical-technical staff. The nurses variable being treated as intermediate could be attributed to the fact that the assistance offered by the nurses is following the medical treatment that the patient receives inside the hospital.

\section{DEA Model for the Separated Sub-Processes}

Outside hospital, patients receive medical care by private professional physicians or other organizations at private clinics and medical assistance at home or at other places. In the hospitals, both activities are offered jointly. However, it could be useful to estimate the efficiency of the two activities as being separately provided within the hospital setting. This could facilitate the exploration of the relationship between them in a relational model as well as its impact on overall efficiency. For each sub-process, analysed individually, we solve the DEA model. In general, DEA is benchmark approach that essentially consists of two tasks: first, the estimation of an efficient frontier using the best observations inside the sample, later, in the DEA envelopment form, the use of a distance function to measure the deviation of each individual observation from this frontier. In the case of "fully efficient" observations, the DEA estimated score is equal to one and all the observations lay on the frontier. If one observation is not on the frontier, it is considered to be inefficient and its DEA score is lower (greater) than 1, in the case of inputs orientation (outputs) measurement and always positive. For $n$ observations and for a vector of $\mathrm{p}$ inputs, $x \in R^{p}$ and q outputs, $y \in R^{q}$ for each one the DEA model (multiplier form) is defined as follows:

$\max \sum_{i=1}^{q} v_{i} y_{i o}$

s.t. $\sum_{i=1}^{p} u_{i} x_{i o}=1$

(Program 2)

$\sum_{i=1}^{q} v_{i} y_{i o}-\sum_{i=1}^{p} u_{i} x_{i o} \leq 0$

$u, v \geq 0$

The objective of (2) is to estimate the optimal values, $\mathrm{u}^{*}$ and $\mathrm{v}^{*}$, that maximize the objective function and satisfy the constraint. The second DEA model assumes CRS, while the VRS model is described below (Program 3):

$$
\begin{aligned}
& \max \sum_{i=1}^{q} v_{i} y_{i o}-v_{o} \\
& \text { s.t. } \sum_{i=1}^{p} u_{i} x_{i o}=1
\end{aligned}
$$


$\sum_{i=1}^{q} v_{i} y_{i o}-\sum_{i=1}^{p} u_{i} x_{i o}-v_{o} e \leq 0$

$u, v \geq 0$.

The DEA's multiplier is calculated on the basis of the optimal weights $\left(\mathrm{u}^{*}\right.$ and $\mathrm{v}^{*}$ ), directly derived from the data. Within this context, "optimal" means that the objective function for each hospital under evaluation (o) is maximized relatively to all other hospitals, with the weights being associated to the inputs and outputs vectors of each hospital. In the following section, we present our DEA model for the medical and assistance activities.

\section{Medical activity DEA Model inputs/outputs}

In general, the objective of the medical activity is to restore the damaged health through surgical operations and/or the provision of other medical services, supported by instrumental or clinical analysis. In the literature, health outcomes and intermediate outputs are clearly different. However, in the efficiency measurement intermediate outputs are also considered. Therefore, in the hospital setting, we can consider the number of surgical interventions as an intermediate output of the surgical care provided to inpatients. The medical care provided to the treated inpatients can also be considered as an intermediate output. Due to lack of data, a proxy of this activity in the days-on hospitals is included in the models. The proxy for the care provision is the availability of beds in the hospital. To evaluate the efficiency of this type of activity within the hospital setting, using the DEA model, it is necessary to define the input and output vectors. To do this, we use the input/outputs in Table 2.

Table 2. DEA Inputs/Outputs Medical Activity, 2011

\begin{tabular}{|l|l|}
\hline \multicolumn{2}{|c|}{ Medical activity } \\
\hline Inputs & Outputs \\
\hline Physicians & Surgical intervention \\
\hline Ordinary beds & Days-on hospitals \\
\hline Day-hospital beds & \\
\hline Day-surgery beds & \\
\hline Medical-technical staff & \\
\hline Source: Authors estimations
\end{tabular}

The DEA-CCRS model solved in the case of the first sub-process (medical services production and provision) is the following:

$$
\begin{aligned}
& \max \sum_{r=1}^{4} u_{y} Y_{r n} \\
& \text { s. } t_{s} \sum_{i=1}^{p} v_{i} X_{i n}=1 .
\end{aligned}
$$


$\sum_{r=1}^{q} u_{y} Y_{r n}-\sum_{\mathrm{I}=1}^{p} v_{\mathrm{i}} X_{\mathrm{in}} \leq 0$

$u_{v} v \geq 0$.

where $n$ is the number of the hospitals $(n=574)$, $q$ the number of outputs of the first sub-process $(q=3)$ and $p$ is the number of the inputs $(p=5)$ (Table 2). The VRS model is also solved for the case of the medical care provision.

Assistance activity DEA Model inputs/outputs

The assistance activity in the hospital setting care is defined as the sum of all the services provided to assist the inpatient after the surgical interventions and/or later/during the provision of other types of medical care. The personnel responsible of providing assistance services are the nurses offering such services at the inpatients during their days in the hospital.

Table 3. DEA Inputs/Outputs Assistance Activity, 2011

\begin{tabular}{|l|l|}
\hline \multicolumn{2}{|c|}{ Assistance activity } \\
\hline Inputs & Outputs \\
\hline Surgical intervention & Ordinary discharges \\
\hline Days-on hospitals & Day-hospital discharges \\
\hline Nurses & Surgical discharges \\
\hline Ordinary beds & \\
\hline Day-hospital beds & \\
\hline Day-surgery beds & \\
\hline
\end{tabular}

Source: Author's estimations.

After the completion of their treatment, the inpatients are discharged from the hospital, with the discharge process being under the supervision of the administrative staff. The following DEA-CRS model has been solved for the second sub-process:

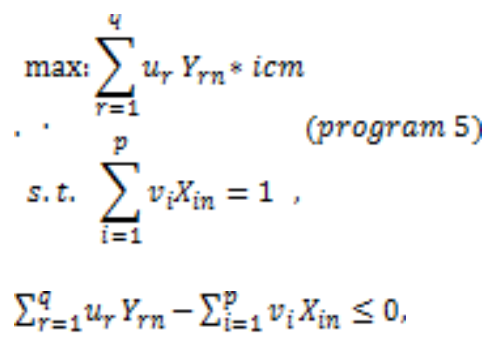

$u_{s} v \geq 0$

where $\mathrm{n}$ is the number of the hospitals (574), q the number of outputs of the first sub-process $(q=3)$ and $p$ the number of the inputs $(p=6)$ (Table 3). The objective function of the program is defined on the basis of the case-mix index weighted discharges. The VRS model has been also applied to the assistance activity case also. 


\section{Data and Descriptive Statistics}

Our sample includes 574 Italian public's hospitals ${ }^{1}$ surveyed in 2011 . For each unit in the sample, there exist data on the physicians (number of hospital's doctors), the nurses (number of assistance's personnel), the medical-technical staff (number of medical-technical employees), the rehabilitative staff (number of rehabilitative employees), the administrative staff (number of administrative employees), other personnel (number of other medical and not medical employees as chemists, biologists, pharmacists etc.), beds in ordinary, dayhospital and day-surgery regimes (number of beds), discharges (number of surgical discharges, ordinary and in-the-day regimes), surgical interventions (number of surgical interventions), days-in-hospital (number of days spent in the hospital), case-mix index (average case mix index calculated considering the average case mix index for each discipline (ICM mean) and case mix at the hospital level (ICM structure) and entropy index. The descriptive statistics of these data are presented in Table 4, including the mean, standard deviation, median, and II, III, IV and V quartiles.

Table 4. Descriptive Statistics of Data Sample (N=574), 2011

\begin{tabular}{|l|c|c|c|c|c|c|c|}
\hline Variables & Mean & Std. Dev. & Median & IIQ & IIIQ & IVQ & VQ \\
\hline Ordinary beds & 290.83 & 289.13 & 185 & 90.25 & 185 & 400 & 1,653 \\
\hline Day-Hospital Beds & 25.775 & 32.17 & 14 & 6 & 14 & 33 & 195 \\
\hline Day-Surgery Beds & 8.8746 & 12.906 & 3 & 0 & 3 & 12 & 69 \\
\hline Physicians & 176.49 & 187.9 & 107 & 46.5 & 107 & 250.5 & 1,104 \\
\hline Nurses & 415.87 & 449.74 & 246 & 107 & 246 & 579.5 & 2,376 \\
\hline Tech-med staff & 62.245 & 73.769 & 34 & 13 & 34 & 85.5 & 457 \\
\hline Teaching & 1.1765 & 7.9292 & 0 & 0 & 0 & 1 & 173 \\
\hline Rehab & 21.958 & 30.32 & 10 & 2 & 10 & 28 & 196 \\
\hline Admin & 67.351 & 101.21 & 29 & 10.5 & 29 & 72 & 798 \\
\hline Other pers. & 193.96 & 238.67 & 105 & 54 & 105 & 226.5 & 1,643 \\
\hline Discharges & 10673 & 10,678 & 7,223 & $2,770.5$ & 7,223 & 14,836 & 62,695 \\
\hline Discharges day hospital & $1,296.4$ & $1,526.7$ & 780 & 217.5 & 780 & $1,724.5$ & 10,538 \\
\hline Surgical discharges & $4,444.5$ & $5,330.7$ & $2,508.5$ & 887.25 & $2,508.5$ & $6,130.3$ & 3,8162 \\
\hline Surgical interventions & 13,407 & 17,030 & $7,452.5$ & $2,672.8$ & $7,452.5$ & 17,730 & 131,605 \\
\hline Days-on hospitals & 83,735 & 85,777 & 50,281 & 24,343 & 50,281 & 118,569 & 502,075 \\
\hline $\begin{array}{l}\text { Pre-operation days-on } \\
\text { hospitals }\end{array}$ & 16,728 & 21,690 & $8,161.5$ & $2,961.5$ & $8,161.5$ & 22,994 & 154,147 \\
\hline ICM mean & 0.9423 & 0.142 & 0.9419 & 0.8633 & 0.9419 & 1.014 & 1.8533 \\
\hline ICM-structure & 0.9348 & 0.1895 & 0.91 & 0.82 & 0.91 & 1.01 & 2.87 \\
\hline Entropy index & 1.9503 & 0.4189 & 2.09 & 1.87 & 2.09 & 2.2275 & 2.44 \\
\hline
\end{tabular}

Source: Author's estimations.

\footnotetext{
${ }^{1}$ The public hospitals considered are the Hospital Trust (Azienda Ospedaliera), the local public hospital directly managed by Local Health Units ( $L H U$ ) (Ospedali a gestione diretta ASL), the public University hospitals (Policlinici Universitari), and the teaching and research hospitals incorporated in the public sector (Istituti di Ricovero e Cura a Carattere Scientifico-IRCCS) covering more than $90 \%$ of the observations. Accredited private hospitals are accredited private nursing home, private University hospitals, private IRCCS, private research institutions, private classified ecclesiastic's hospitals.
} 
The physicians in the sample are about 176 while the nurses are 416 . The public structures have on average a Case Mix Index (CMI) of 0.9348, while the average CMI among the disciplines is approximately 0.942, with both of them being below the standard CMI (=1). In other words, in 2011, the public structures treated cases less complex than the national standards. However, the structures are characterised by high diversification, with the entropy index being larger than one. The volume of the sample public structures' activity developed in 2011 accounts to 10,673 ordinary discharges, 1,269 discharges in day-on hospital regime and 4,444 surgical discharges. The surgical interventions are measured to be 13,407 and the days-on hospitals are 83,735. The average numbers of beds used for each activity are the following: 290.8 ordinary beds, 25.7 day-hospital beds and 8.8 days-surgery beds.

\section{Results}

The input orientation drives all the measurements. The second sub-process efficiency is obtained using the decomposition formula of the efficiency measurement (Kao 2009a), and the efficiency of the acute care relational process is derived a solution to the DEA-network model. At the same time, both constant (CRS) and variable returns to scale (VRS) are assumed for the efficient frontier estimates. The results from these estimations are shown in Table 5.

In Table 5, the average relational efficiency measures for the acute care service production process and its sub-processes are reported. The relational efficiency and the medical sub-process efficiency, referred to as sub-process 1 in the network system presented in Figure 1, are calculated on the basis of the DEA network model and the DEA model respectively. The efficiency of the assistance activities, referred to as sub-process 2 in the Figure 1, is calculated using the decomposition formula (Kao 2009a). The average relational efficiency is obtained by the application of the arithmetic mean at each efficiency vector. On average, the production process of the acute care services has relational efficiency of the $0.46 \%$ level under the CRS assumption and relational efficiency of the $0.85 \%$ level under the VRS assumption. The majority of processes are characterized by estimated efficiency falling in the $0.4-0.6 \%$ range (Figure 2) under CRS, and within the $0.4-0.5 \%$ range considering VRS $^{1}$ (Figure 3).

Separate measurements of the "medical" and "assistance" activities, without considering the relationships developing between them within the network model, are presented in the following section. Both CRS and VRS assumption are made for all measurements while bootstrapped efficiency core intervals of confidence are also constructed for each measure.

\footnotetext{
${ }^{1}$ Because of the presence of some outliers (relational efficiency >3) the histogram consider 561 of 574 observations.
} 
Table 5. Descriptive Statistics of the Acute Care Processes' and SubProcesses' Efficiency in the Relational Model, 2011

\begin{tabular}{|c|c|c|c|}
\hline & \multicolumn{3}{|c|}{ RTS assumption } \\
\hline Descriptive statistics & \multicolumn{3}{|c|}{ CRS } \\
\hline & System & First sub-process & Second sub-process \\
\hline Mean & 0.4588 & 0.5099 & 0.9307 \\
\hline S.D & 0.2432 & 0.1799 & 0.3566 \\
\hline Median & 0.4358 & 0.4770 & 0.9437 \\
\hline IIQ & 0.3284 & 0.3957 & 0.7829 \\
\hline IIIQ & 0.4358 & 0.4770 & 0.9437 \\
\hline IVQ & 0.5473 & 0.5655 & 1.0988 \\
\hline lowi.c.EXP & 0.4611 & 0.5122 & 0.9330 \\
\hline highi.c.EXP & 0.4615 & 0.5126 & 0.9334 \\
\hline lowi.c.TRUNCNORM & 0.4693 & 0.5204 & 0.9301 \\
\hline highi.c.TRUNCNORM & 0.4705 & 0.5216 & 0.9313 \\
\hline lowi.c.HALFNORMAL & 0.3838 & 0.5136 & 0.9345 \\
\hline \multirow{2}{*}{ highi.c.HALFNORMAL } & 0.3842 & 0.5141 & 0.9350 \\
\hline & \multicolumn{3}{|c|}{ VRS } \\
\hline Mean & 0.8493 & 0.5945 & $1.2218^{1}$ \\
\hline S.D & 8.3760 & 0.2238 & 8.3632 \\
\hline Median & 0.4478 & 0.5346 & 0.8956 \\
\hline IIQ & 0.3253 & 0.4153 & 0.6973 \\
\hline IIIQ & 0.4478 & 0.5346 & 0.8956 \\
\hline IVQ & 0.6009 & 0.7370 & 1.0316 \\
\hline lowi.c.EXP & 0.8516 & 0.6041 & 1.2241 \\
\hline $\begin{array}{c}\text { highi.c.EXP } \\
\end{array}$ & 0.8520 & 0.6049 & 1.2245 \\
\hline lowi.c.TRUNCNORM & 0.8598 & 0.6041 & 1.2323 \\
\hline highi.c.TRUNCNORM & 0.8610 & 0.6049 & 1.2335 \\
\hline lowi.c.HALFNORMAL & 0.8531 & 0.6041 & 1.2255 \\
\hline highi.c.HALFNORMAL & 0.8535 & 0.6049 & 1.2260 \\
\hline
\end{tabular}

Source: Author's estimations.

Note: The abbreviation low is lower and high is higher; i.c. stands for interval of confidence; TRUNCNORM is the abbreviation of truncated normal distribution; HALNORMAL for half normal distribution and EXP for exponential distribution.

\section{The Efficiency of the Sub-Process as Independent Measurements}

Indisputably, learning is one of the main ways for improving performance. Within the context of our baseline approach, the best practices have efficiency scores lying on the estimated frontier. With this consideration being the start point, the efficiency of two independent sub-processes is calculated (Seiford and Zhu 1999). Before considering the relationship between them, some policy indications are discussed. The descriptive statistics of the results of the subprocesses efficiency measurement are shown in Table 6.

\footnotetext{
${ }^{1}$ Eliminating outliers values (eff $>3$ ) on average the relational efficiency of assistance activity is of 0.88 with s.d. of 0.33 .
} 
Figure 2. Histogram of Acute Care Service' Relational Efficiency (CRS)

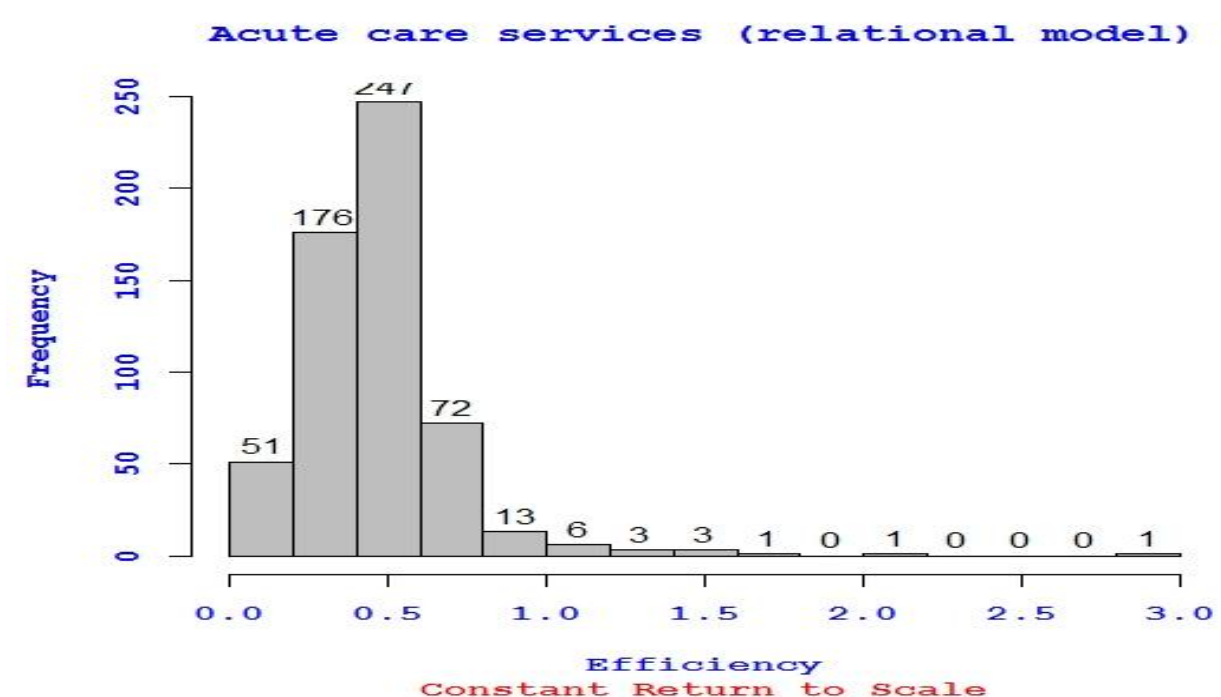

Source: Author's estimations.

Figure 3. Histogram of Acute Care Service' Relational Efficiency (VRS)

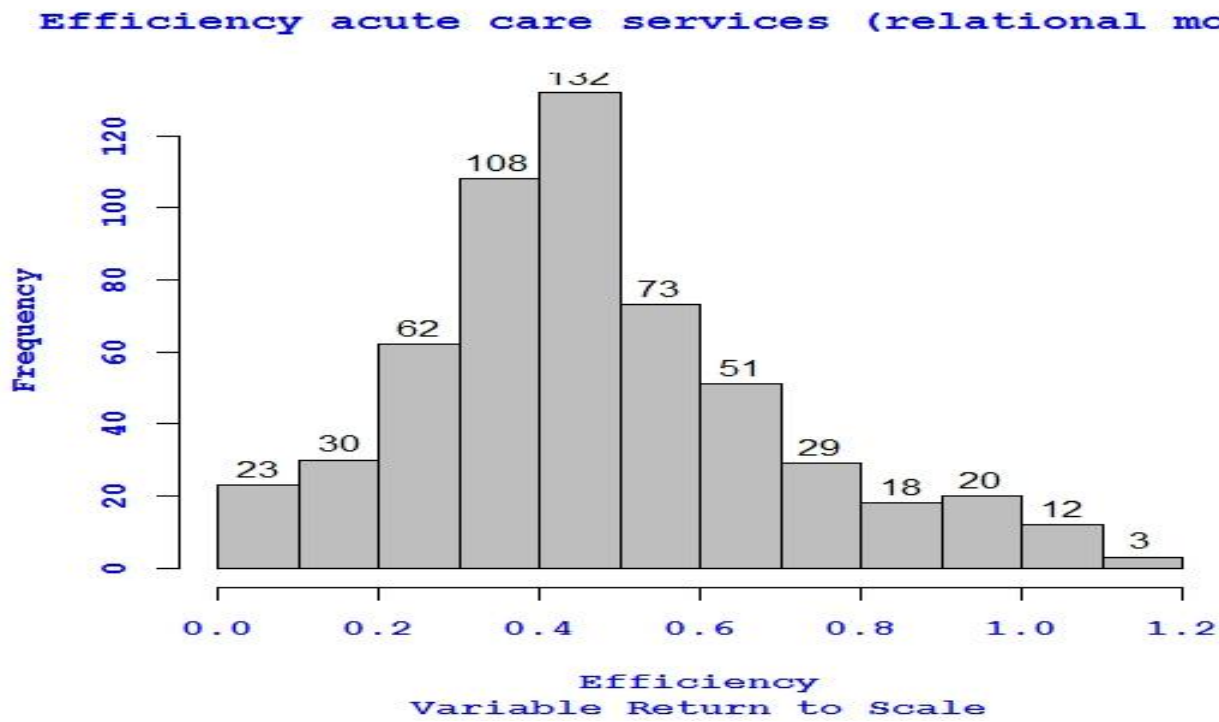

Source: Author's estimations.

Under the CRS assumption, medical activities utilize about 0.485 times the overall input amount required to produce current days-in-hospital services and surgical interventions. Moreover, the assistance sub-process demonstrates efficiency of approximately the 0.647 level. Under the VRS assumption, we estimated efficiency levels of the 0.564 and 0.707 level, respectively. Based on these results, assistance activities appear to be more efficient than medical activities. 
Table 6. Descriptive Statistics of the Sub-Process Efficiency Results, 2011

\begin{tabular}{|c|c|c|}
\hline & \multicolumn{2}{|c|}{ RTS assumption } \\
\hline Descriptive statistics & \multicolumn{2}{|c|}{ CRS } \\
\hline & Medical sub-process & Assistance sub-process \\
\hline Mean & 0,485493678 & 0,64735 \\
\hline S.D & 0,169094976 & 0,17948 \\
\hline Median & 0,468737622 & 0,63719 \\
\hline IIQ & 0,383866653 & 0,53114 \\
\hline IIIQ & 0,468737622 & 0,63719 \\
\hline IVQ & 0,553753654 & 0,75328 \\
\hline lowi.c.EXP & 0,487776701 & 0,64966 \\
\hline $\begin{array}{c}\text { highi.c.EXP } \\
\end{array}$ & 0,488232128 & 0,65005 \\
\hline lowi.c.TRUNCNORM & 0,496033303 & 0,65789 \\
\hline highi.c.TRUNCNORM & 0,497179627 & 0,65905 \\
\hline lowi.c.HALFNORMAL & 0,489246905 & 0,65109 \\
\hline \multirow[t]{2}{*}{ highi.c.HALFNORMAL } & 0,489737829 & 0,65163 \\
\hline & \multicolumn{2}{|c|}{ VRS } \\
\hline Mean & 0,56424115 & 0,70682 \\
\hline S.D & 0,210071248 & 0,18396 \\
\hline Median & 0,52020775 & 0,68821 \\
\hline IIQ & 0,407586658 & 0,57041 \\
\hline IIIQ & 0,52020775 & 0,68821 \\
\hline IVQ & 0,692322631 & 0,84685 \\
\hline lowi.c.EXP & 0,573805483 & 0,70911 \\
\hline $\begin{array}{l}\text { highi.c.EXP } \\
\end{array}$ & 0,57465629 & 0,70953 \\
\hline lowi.c.TRUNCNORM & 0,573805606 & 0,71730 \\
\hline highi.c.TRUNCNORM & 0,574656911 & 0,71857 \\
\hline lowi.c.HALFNORMAL & 0,573805851 & 0,71056 \\
\hline highi.c.HALFNORMAL & 0,574656092 & 0,71107 \\
\hline
\end{tabular}

Source: Author's estimations.

Note: The abbreviation low is lower and high is higher; i.c. stands for interval of confidence; TRUNCNORM is the abbreviation of truncated normal distribution; HALNORMAL for half normal distribution and EXP for exponential distribution.

The DEA Standard Model vs the DEA Network Model: Testing the "Relationship Effect"

To test the hypothesis that the modeled relationship between the subprocesses influences the efficiency measurement, we compare our relational efficiency results, presented in Table 5, with the DEA efficiency score, shown in Table 7 using several statistical tests, described in Table 8.

We consider the following statistical tests: 1) the Kolmogorov-Smirnov, 2) the Kruskall- Wallais and 3) the Wilcox sum rank test. The p-values as well as the statistical values of the statistical tests are shown in Table 8 . The statistical tests are conducted using the two distributions of DEA and DEA network models under the CRS and VRS assumptions, respectively. The values of the statistical tests suggest that the interrelation between the two sub-processes, as modeled in the present study, is not independent to the efficiency measurement. 
Table 7. Descriptive Statistics of DEA Efficiency Results, 2011

\begin{tabular}{|c|c|c|}
\hline Descriptive statistics & \multicolumn{2}{|c|}{ RTS assumption } \\
\hline Mean & CRS & VRS \\
\hline S.D & 0.590313398 & 0.655431165 \\
\hline Median & 0.177782784 & 0.194250502 \\
\hline IIQ & 0.570543612 & 0.614681984 \\
\hline IIIQ & 0.483759666 & 0.51537262 \\
\hline IVQ & 0.570543612 & 0.61468198 \\
\hline lowi.c.EXP & 0.663305842 & 0.77760918 \\
\hline highi.c.EXP & -3.799661918 & 0.80416072 \\
\hline lowi.c.TRUNCNORM & -3.798821165 & 0.80496739 \\
\hline highi.c.TRUNCNORM & -3.799660624 & 0.65502867 \\
\hline lowi.c.HALFNORMAL & -3.798820729 & 0.65583517 \\
\hline highi.c.HALFNORMAL & -3.799661859 & 0.66503199 \\
\hline Sowit. & -3.79882151 & 0.66583761 \\
\hline
\end{tabular}

Source: Author's estimations.

Note: The abbreviation low is lower and high is higher; i.c. stands for interval of confidence; TRUNCNORM is the abbreviation of truncated normal distribution; HALNORMAL for half normal distribution and EXP for exponential distribution.

Table 8. Statistical Test Results and Rank Correlation

\begin{tabular}{|c|c|c|}
\hline Model & \multicolumn{2}{|c|}{ Test } \\
\hline \multirow[t]{9}{*}{ CRS } & Statistic value & p-value \\
\hline & \multicolumn{2}{|c|}{ Kolmogorov-Smirnov } \\
\hline & 0.700348432 & 0 \\
\hline & \multicolumn{2}{|c|}{ Wallais } \\
\hline & 292231 & $45938 \mathrm{E}-114$ \\
\hline & \multicolumn{2}{|c|}{ Kruscal-wallais } \\
\hline & 5731368189 & 0.490531695 \\
\hline & \multicolumn{2}{|c|}{ Rank correlation } \\
\hline & \multicolumn{2}{|c|}{0.471793437} \\
\hline VRS & \multicolumn{2}{|c|}{ Kolmogorov-Smirnov } \\
\hline & 0.695121951 & 0 \\
\hline & \multicolumn{2}{|c|}{ Wallais } \\
\hline & 2888305 & 3.6274E-108 \\
\hline & \multicolumn{2}{|c|}{ Kruscal-wallais } \\
\hline & 573.9361505 & 0.388108036 \\
\hline
\end{tabular}

Source: Author's estimations.

Note: The abbreviation low is lower and high is higher; i.c. stands for interval of confidence; TRUNCNORM is the abbreviation of truncated normal distribution; HALNORMAL for half normal distribution and EXP for exponential distribution.

Prevailing Returns to Scale

DEA models can be formulated in such a way as to allow for the analysis of the returns to scale involved in the activities under study using the following Banker-Charnes-Cooper (BCC) model (Banker et al. 1984, Cooper et al. 2007): 


$$
\begin{array}{cc}
\max & u y_{0}-u_{\circ} \\
\text { s.t. } v x_{0}=1 & (\text { program 6) }
\end{array}
$$

$-v X+u Y-u_{o} e \leq 0$

$v \geq 0, u \geq 0, u_{\circ}$ free in sing

In the above program, if $u_{o}^{*}<0$, increasing return scale (IRS) prevail at operation of units lying on the frontier. If $u_{o}^{*}>0$, decreasing returns to scale (DRS) are prevalent and if $u_{\circ}^{*}=0$ constant returns to scale (CRS) are dominant. To evaluate the nature of the prevailing returns to scale for the units operating within the feasible set but not on the frontier, the latter's projection point is used to define the prevailing return to scale:

$$
\widehat{x_{\text {io }}}=\theta^{*} x_{\text {io }}-s_{i}^{-*} \text {, }
$$

where $\theta^{*}$ and $s_{i}^{-*}$ are solutions to equation (1). In this section, we apply the above condition at all VRS models to explore the prevailing returns to scale. The production process of acute care services treated as a network of two subprocessed is characterized by constant return to scale as shown in Table 9. When the DEA model is used, VRS appear to prevail.

Table 9. Proportion of Prevailing Return to Scale, 2011

\begin{tabular}{|c|c|c|c|c|}
\hline Return to scale & DEA Network & $\begin{array}{c}\text { Medical sub- } \\
\text { process }\end{array}$ & $\begin{array}{c}\text { Assistance sub- } \\
\text { process }\end{array}$ & DEA \\
\hline CRS & 80,3135889 & 1,56794425 & 6,62020906 & 4,18118467 \\
\hline IRS & 19,6864111 & 38,1533101 & 50,6968641 & 50,5226481 \\
\hline DRS & 0 & 60,2787456 & 42,6829268 & 45,2961672 \\
\hline Full efficienct & 0 & 0,05574913 & 0,06271777 & 0,06271777 \\
\hline Over full efficient & 0,05052265 & & & \\
\hline
\end{tabular}

Source: Author's estimations.

Looking at Table 9, we know that for DEA network model, the prevailing returns to scale are constant ( $80.313 \%$ of the observations). In the medical process, DRS prevail while in the assistance process, both IRS and DRS prevails. Finally, the DEA model demonstrates both IRS and DRS.

\section{Discussion and Conclusions}

The present paper studies the alternative approaches to the measurement of hospital services efficiency. Developing a relational model, we conceptualize the production process of the acute care services as a network consisting of two sub-processes: the medical and the assistance services provision to the acute inpatients. Medical services are offered to patients in need of surgical operations, generally classified with a surgical DRG, and inpatients in need of medical care, generally classified with a medical DRG. All hospital treated cases, with the recipients of treatment referred to as inpatients, receive assistance services before 
discharge and medical treatment after being discharged. This paper's contribution to the health economics literature and particularly the literature focusing on the Italian hospitals lies in the innovations that follow: 1) estimation of relational efficiency, 2) application of the DEA network for specific hospital services (e.g., acute care) overcoming the data aggregation problem in the evaluation of the hospital efficiency, 3) distinguishing between the efficiency of the hospital medical services from the efficiency of the assistance services using individual efficiency measures, 4) conceptualization of the production process of the hospital acute services as a network consisting of two sub-processes, 5) setting the basis for more precise policy indications.

The limits of the study are associated to the general limits imposed by the DEA itself (Daraio and Simar 2008) as well as to the linear relationship that the DEA network assumes between the two sub-processes as stated in the paper by Kawaguchi et al. (2014), which considers two different types of hospital processes: medical and administrative.

Two DEA programs (program 2 and 3) have been used to estimate the efficiency of the production process of acute care services without considering the relationships between them, as well as for the efficiency of the two activities separately. All DEA models assume that there exists technology of both constant and variable returns to scale. In order to analyze the relationship between the two types of activities involved in acute hospital care, a DEA network program is used to estimate their efficiency. Our relational model is a network of two subprocesses based on the same technology. To explore the prevailing returns to scale, a specific BCC model is used for both sub-processes and all models. The results allow us, trough the statistical tests presented in Table 8, to compare the efficiency score distribution of the production process of acute care service, considered as a "black box", estimated with a DEA model, to the relational efficiency score distribution, estimated with the DEA network model proposed here. According to the statistical tests, the null hypothesis of the two distributions being the same, is rejected, concluding that these differences can be useful to support the adoption of the relational model for the efficiency measurement. Measuring the efficiency scores with respect to the type of returns to scale being in operation could be proven very useful for policy design. For example, the first sub-process, i.e. medical activity demonstrates an efficiency of $59.4 \%$ on average while the increasing returns to scale account for $60.2 \%$ of all the sub-processes considered in the sample. This evidence suggests that there is a 0.6 probability that increasing the scale of the medical care provision by increasing the surgical interventions and the day-in-hospital services observed in the 2011 could be associated to a decrease in the average costs. The second sub-process demonstrates average efficiency of 0.707 in the VRS model with the increasing and decreasing returns to scale being in operation. Here we have two different policy indications: limiting and broadening the assistance sub-process. When the relationship between the two sub-processes is taken under consideration, the second sub-process, involving assistance activities, is estimated to have VRS-efficiency of 0.93 and CRSefficiency equal to 1.22 while both increasing and decreasing returns to scale 
appear to prevail as shown in Table 9. In the case of the absence of any type of relationship, the efficiency of the whole process is estimated to be around 0.655 (DEA-VRS model) while IRS (in about 45 case out of 100) and DRS (in about 50.5 cases out of 100) are dominant. In the case of the relational model, relational efficiency is found to be equal to 0.84 while CRS prevail (in about 80 cases out of 100). These differences emerging from the different assumptions regarding the type of the returns to scale have quite important policy implications. In the case where a relational model is considered to best fit the real hospital conditions, there does not occur any scale dimension adjustment with the inputs system level only being adjusting. Compared with the results in the paper by Kawaguchi et al. (2014), the efficiency of medical activity provided by public Italian hospitals operating under VRS $(0.854)$ is on average very similar to the case of Japanese hospitals (efficiency measures were 0.858 in 2007 and 0.870 in 2009). What should be noted here is that relational efficiency is positively correlated with the hospital's size as shown in Figure 4.

Figure 4. Scatter Plot and Regression Line Between Relational Efficiency Scores and Hospital Size (Measured with Total Beds)
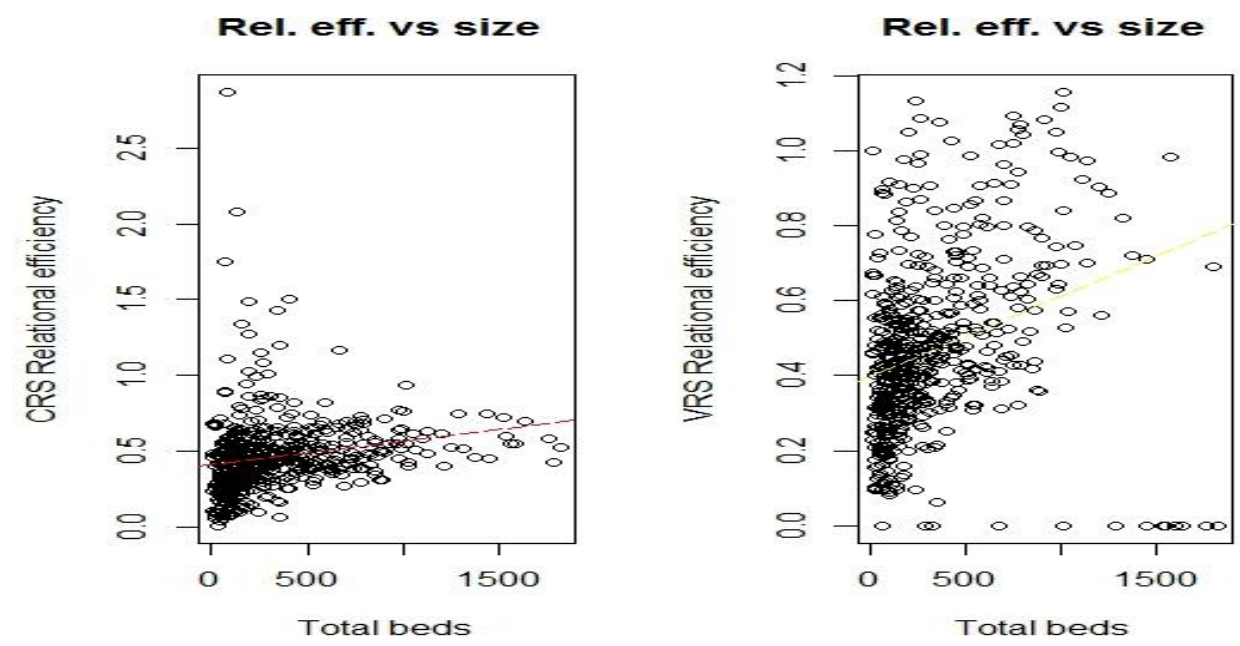

Source: Author's estimations.

In both the cases of the CRS and VRS models, relational efficiency is positively correlated to hospital size, proxied by the total number of beds ${ }^{1}$. Figure 4 shows that, in only a few cases the relational efficiency of high quality acute care production $(>0.9)$ is found in hospitals with less than 250 beds (Barbetta and Zago 2007). This could reflect the existence of a positive synergy effect of the relation between medical and assistance activity in small and middle size hospitals. However, in both relational models (CRS and VRS), hospitals with $0-250$ beds demonstrate lower relational efficiency (0-0.6\%) Looking at Figure 4, a health policy implication emerges as it appears possible to improve the efficiency of the small and middle size hospitals (beds <250) by

1 The VRS relational efficiency show several outliers values. To draw the scatter plot observations with relational efficiency $>1.2$ are deleted (13 observations) to better figure. 
exploiting the positive synergies involved in the relationship between the two activities of the acute care production process. The above correlation analysis does not take under consideration that larger hospital size could be associated to constant health personnel, physicians and nurses, and volume of activity, discharges and surgical interventions. To include this element in the analysis, we estimate an econometric model where the dependent variable is relational efficiency while the proxy for hospital size and many control variables such as the number of physicians and nurses, discharges and days-in-hospitals measures serve as the regressors. The fact that each hospital treats cases of different complexity is also controlled for by including the case-mix-index. The econometric model is:

$$
\text { rel. eff }=\alpha+\beta X+u \quad(\text { Model 1) }
$$

where,

$$
\begin{aligned}
& \text { rel.eff }=\text { rel.eff } \quad \text { if } 0<\text { rel.eff }<1 \\
& \text { rel.eff }=0 \quad \text { otherwise }
\end{aligned}
$$

A censored Tobit estimation technique is implemented for the estimation of the above model. The estimation results are presented in Table 10.

Table 10. Second Stage Analysis, 2011

\begin{tabular}{|l|c|c|c|c|}
\hline Dependent Variables & $\begin{array}{c}\text { Relational } \\
\text { Efficiency } \\
\text { CRS }\end{array}$ & CI 95\% & $\begin{array}{c}\text { Relational } \\
\text { Efficiency } \\
\text { VRS }\end{array}$ & CI 95\% \\
\hline Total beds & $\mathbf{- 0 . 0 0 0 9 6 0 8}$ & $\mathbf{- 0 . 0 0 1 2 3 8}$ & $\mathbf{- 0 . 0 0 1 4 1 8 7}$ & $\mathbf{- 0 . 0 0 1 8 3 2 4}$ \\
& $(0.0001414)$ & $\mathbf{- 0 . 0 0 0 6 8 3}$ & $(0.0002106)$ & $\mathbf{- 0 . 0 0 1 0 0 5}$ \\
\hline Total discharges & 0.00002 & 0.0000163 & 0.000015 & $9.64 \mathrm{e}-06$ \\
& $(1.87 \mathrm{E}-6)$ & 0.0000237 & $(2.72 \mathrm{e}-06)$ & 0.0000203 \\
\hline Physicians & 0.0001434 & -0.0000981 & 0.000204 & -0.0001491 \\
& $(0.000123)$ & 0.0003849 & $(0.0001798)$ & 0.0005572 \\
\hline Nurses & -0.0000407 & -0.0001695 & 0.0000471 & -0.0001397 \\
& $(0.0000656)$ & 0.000088 & $(0.0000951)$ & 0.0002339 \\
\hline Days-on-hospitals & $4.45 \mathrm{e}-07$ & $-4.84 \mathrm{e}-07$ & $2.49 \mathrm{e}-06$ & $1.12 \mathrm{e}-06$ \\
& $(4.73 \mathrm{e}-07)$ & $1.37 \mathrm{e}-06$ & $(6.99 \mathrm{e}-07)$ & $3.86 \mathrm{e}-06$ \\
\hline Surgical interventions & $-2.11 \mathrm{e}-06$ & $-3.94 \mathrm{e}-06$ & $-7.12 \mathrm{e}-07$ & $-3.44 \mathrm{e}-06$ \\
& $(9.31 \mathrm{e}-07)$ & $-2.83 \mathrm{e}-07$ & $(1.39 \mathrm{e}-06)$ & $2.01 \mathrm{e}-06$ \\
\hline Case-Mix-Index & 0.4633208 & 0.3688881 & 0.4284779 & 0.2929783 \\
& $(0.048078)$ & 0.5577535 & $(0.068986)$ & 0.5639776 \\
\hline No of observations & 574 & & 574 & \\
\hline LR test & 159.72 & & 281.62 & \\
\hline Sour & \multicolumn{3}{|l}{} \\
\hline
\end{tabular}

Source: Author's estimations.

As shown in Table 10, the effect of size on relational efficiency is negative and low in magnitude, but statistically significant ${ }^{1}$. This contradict conclusion

\footnotetext{
${ }^{1}$ Our interest is not of statistics nature, so we limit to see if the estimated parameter of the variable of interest is statistically significant. However some problem of multicollinearity can exist in the econometric model.
} 
drawn from the correlation analysis above, leading to different policy considerations. In the light of the correlation results, increasing the hospital size, while physicians, nurses, and volume of activity remain constant (ceteris paribus condition), causes relational efficiency to decrease. This could be attributed to the fact that an increase in the hospital size does not facilitate the exploitation of the possible positive synergies emerging from the relationship between physicians and nurses, while it does note ensure effective coordination among whole hospital's personnel. The coordination mechanism in hospitals of smaller size is rather different than more effective. In this sense, the policy implications change in the following manner: if the hospital's size (number of beds) is increased, then the number of personnel should be also increased in proportion to the volume of activities undertaken in the hospital in order to exploit possible positive synergies. Additionally, another important aspect in terms of the policies to be implemented is found at the micro level.

We believe that the relational model proposed here, as well as every other similar relational model, enables to draw more efficient policy to better manage clinical risk, particularly for the staff and organizational structure (Chesi et al. 2015) compared to the DEA models. In fact, the DEA model brings together all the input and output variables in one side, without being able to distinguish between the different contribution of doctors and nurses. A DEA model treats both physicians and nurses in the same manner, putting them in the same input vector. In this context, it also treats surgery interventions and discharges as an aggregated sum of output (Table 11).

Table 11. DEA Inputs and Outputs

\begin{tabular}{|c|c|}
\hline \multicolumn{2}{|c|}{ DEA } \\
\hline Inputs & Outputs \\
\hline Medical-technical staff & Ordinary discharges \\
\hline Physicians & Day-hospital discharges \\
\hline Nurses & Surgical discharges \\
\hline Ordinary beds & Days on hospitals \\
\hline Day-hospital beds & Surgical interventions \\
\hline Day-surgery beds & \\
\hline
\end{tabular}

Source: Author's estimations.

The relational model, presented in Figure 1 and Table 1 , overcomes this limitation imposed by the DEA model. In conclusion, the main contribution of this paper is the conceptualization of the production of the hospital's acute care service as process influenced by the relationship developing between the medical and assistance activities. Each type of activity is based on its own technology while they both share common resources, such as beds. In this context, the efficiency of each activity is measured separately. For the efficiency estimation, an ad-hoc DEA network model program (program 1) is solved. We also consider the efficiency of the two activities individually (programs 2 and 4). In addition, for all measurements, derived from both the CRS and VRS models, a sensitivity analysis has also been conducted using a bootstrap technique. To test if the specific modeling of the relationship between the activities fits the real hospital 
conditions, different statistical test are conducted on the basis of the distribution efficiency scores derived from the DEA and DEA network models. Having tested the statistical significance of the effect (Table 8), the paper explores the prevailing returns to scale in the two activities (medical and assistance) as well as in the network of the acute care, and the effect of hospital's size on relational efficiency. The latter is identified on the basis various methods, such as correlation analysis and econometric model estimation (Model 1). In summary, important policy implications are developed both at the macro and micro level. Probably, the limits of this study mainly lay in the lack of more and higher quality data to better individuate the inputs and outputs for other hospital services and model their relationship, as well as formalize an adequate DEA network program. Finally, better data would allow for the inclusion of external factors influencing relational efficiency.

\section{Acknowledgments}

Our thanks to the "University of Salerno".

\section{References}

Aletras V, Kontodimopoulos N, Zagouldoudis A, Niakas D (2007) The short-term effect on technical and scale efficiency of establishing regional health systems and general management in Greek NHS hospitals. Health Policy 83(2-3): 236-245.

Athanassopoulos A, Gounaris C, Sissouras A (1999) A descriptive assesment of the production and cost efficiency of general hospitals in Greece. Health Care Management Sciences 2(2): 97-106.

Banker R, Charnes A, Cooper W (1984) Some models for estimating technical and scale inefficiencies in data envelopment analysis. Mangement Science 30(9): 1078-1092.

Barbetta GGT, Zago A (2007) Behavioral Differences Between Public and Private bot-fro-profit Hospitals in the Italian national Health Service. Health Economics 16(1): 75-96.

Bordignon M, Mapelli V, Turati G (2002) Fiscal federalism and national health services in the Italian system of governments. ROMA: ISAE.

Cellini R, Pignataro G, Rizzo I (2000) Competition and Efficiency in Health Care: An Analysis of the Italian Case. Internatinal Tax and Public Finance 7(4-5): 503-519.

Chesi G, Maccari S, Nardi R, Volpi R (2015) Organico, distribuzione del personale, sovraffollamento delle corsie ospedaliere in ambito internistico: quali riorganizzazioni auspicabili per ridurre il rischio clinico? Analisi della letteratura e riflessioni a partire da esperienze della Regione Emilia (Staff, staff distribution, overcrowding of hospital wards in nursing wards: scope which desirable restructuring to reduce the clinical risk? Literature analysis and reflection from experience of Region Emilia). Politiche Sanitarie 16(2): 101-111.

Cooper WW, Seiford LM, Tone K (2007) Data Envelopment Analysis. A Comprehensive Text with Models, Application, References and DEA-Solver Software. New York: Springer.

Daraio C, Simar L (2008) Advanced Robust and Nonparametric Methods in Efficiency Analysis. Methodology and Applications. Springer. 
Deprins D, Simar L, Tulkens H (1984) Measuring Labor-Efficiency in Post Office. In: The performance of Public Interprises: Concepts and Measurement. (243-267). Amsterdam.

Fare R, Grosskopf S (2000) Network DEA. Socio-Economics Planning Sciences 34(1): 35-49.

Fattore G, Torbica A (2006) Impatient reimbursment system in Italy: How do tariffs relate to costs?. Health Care Management Sciences 9(3): 251-258.

France G, Taroni F, Donatini A (2005) The Italian health-care system. Health Economics 14(S1): S187-S202.

Gerdtham U-G, Lothgren M, Tambour M, Rehnberg C (1998) Internal Market and Health Care Efficiency. A Multiple-output Stochastic Frontier Analysis. Stockholm School of Economics.

Giokas I (2001) Greek hospitals: how well their resources are used. Omega 29: 73-83.

Grosskopf S, Valdmanis V (1993) Evaluating Hospital performance With Case-MixAdjusted Outputs. Medical Care 31(6): 525-532.

Hollingsworth B (2008) The measurement of efficiency and productivity in the health delivery. Health Economics 17(10): 1107-1128.

Kao C (2009a) Efficiency decomposition in network data envelopment analysis: A relational model. European Journal of Operational Research 192(3): 949-962.

Kao C (2009b) Efficiency mesurement for parallel production systems. European Journal of Operational Research 196(3): 1107-1112.

Kao C (2014) Efficiency decomposition for general multi-stage systems in data envelopment analysis. European Journal of Operational Research 232(1): 117-124.

Kao C, Hwang S-N (2008) Efficiency decomposition in two-stage data envelopment analysis: An application to non-life insurance companies in Taiwan. European Journal of Operational Research 185(1): 418-429.

Kawaguchi H, Tone K, Tsutsui M (2014) Estimation of the efficiency of Japanese hospitals using dynamic and network Data envelopment Analysis model. Health Care Management Sciences 17(2): 101-112.

Kontodimopoulos N, Nanos, P, Niakas D (2006) Balancing efficiency of health services and equity of access in remote areas in Greece. Health Policy 76(1): 49-57.

Liu J, Lu L, Lu W-M, Lin B (2013) A survey of DEA applications. Omega 41(5): 893902.

Lyroudi K, Glaveli N, Koulakiotis A, Angelidis D (2006) The productive performance of public hospitals clinics in Greece: a case study. Halth Services Management Research 19(2): 67-72.

O’Neill L, Rauner M, Heidenberger K, Kraus M (2008) A cross-national comparison and taxonomy of DEA-based hospital efficiency studies. Socioeconomic Planning Sciences 42(3): 158-189.

Ozcan Y, Luke R, Haksever C (1992) Ownership and organizational performance:a comparison of technical efficiency across hopsital types. Medical Care 30(9): 781794.

Pinto C (2014) Severity of illness in the case-mix specification and performance: A study for Italian public hospitals. Journal of Hospital Administration 3(1): 23-33.

Seiford L, Zhu J (1999) Profitability and marketability of the top 55 US commercial banks. Management Sciences 45(9): 1270-1288.

Siciliani L (2006) Estimating Technical Efficiency in the Hospital Sector with Panel Data. Applied Health Economics and Health Policy 5(2): 99-16.

Taroni F (1996) DRG/ROD e nuovo sistema di finanziamento degli ospedali (DRG/ROD and a new hospitals financing system). Roma: Il Pensiero Scientifico. 